\title{
A thoracic vertebral localization of a metastasized cutaneous Merkel cell carcinoma: Case report and review of literature
}

\author{
Rosario Maugeri, Antonella Giugno, Roberto G. Giammalva, Carlo Gulì, Luigi Basile, \\ Francesca Graziano, Domenico G. Iacopino \\ Department of Experimental Biomedicine and Clinical Neurosciences, School of Medicine, Neurosurgical Clinic, University of Palermo, Palermo, Italy \\ E-mail: *Rosario Maugeri - Rosario.maugeri1977@gmail.com; Antonella Giugno - alfagamma82@libero.it; Roberto G. Giammalva - robertogiammalva@live.it; \\ Carlo Guli - carlogul@yahoo.it; Luigi Basile - lbasile64@libero.it; Francesca Graziano - Francesca.graziano03@unipa.it; \\ Domenico G. Iacopino - Gerardo.iacopino@gmail.com \\ *Corresponding author
}

Received: 16 February $17 \quad$ Accepted: 06 June $17 \quad$ Published: 10 August 17

\begin{abstract}
Background: Merkel cell carcinoma (MCC) is a rare neuroendocrine skin tumor, which may be related to sun exposure. It can metastasize to lungs, liver and bone, leading to severe morbidity and mortality. Vertebral metastases from MCC are rare. The authors report the tenth case in the literature, a 59-year-old patient with MCC, which was primarily localized in the scalp, and later provoked distant metastasis to the thoracic spinal column.

Case Description: A 59-year-old woman was admitted at our Unit of Neurosurgery with a 4-month history of progressive and severe dorsal back pain, without neurological signs. The patient had been surgically treated for a recidivated MCC in the occipital region in 2007, 2011, and 2013. (In 2013, the surgical treatment also included lateral cervical lymph node dissection). Chemotherapy and radiotherapy had come after the treatments. Magnetic resonance imaging (MRI) of the dorsal spine showed metastatic vertebral involvement with cord impingement of the T7-T8 levels. A total body CT scan revealed lungs and liver metastases, besides vertebral district. After a multidisciplinary consult a palliative surgery was decided and a posterior dorsal approach was employed: Radiofrequency (RF) thermoablation was followed by the injection of cement of T7 and T8 and transpedicle fixation T5-T9. The postoperative course was uneventful and followed by a further adjuvant therapy Conclusion: Spinal metastases from MCC are described in literature only exceptionally. The clinical course is presented, along with a review of literature.
\end{abstract}

Key Words: Merkel cell carcinoma, radiofrequency thermoablation, spinal metastasis

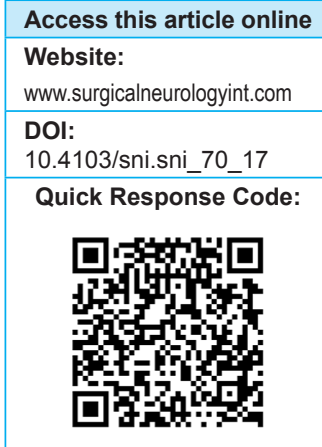

\section{INTRODUCTION}

Merkel cell carcinoma (MCC) is a rare malignant and aggressive neuroendocrine cutaneous tumor, with a poor prognosis, firstly described by Friedrich Sigmund Merkel in 1875. ${ }^{[14]}$ Approximately 0.3-0.6/100.000 MCCs are diagnosed annually in the United States, moreover, the incidence has been increasing in the last
This is an open access article distributed under the terms of the Creative Commons Attribution-NonCommercial-ShareAlike 3.0 License, which allows others to remix, tweak, and build upon the work non-commercially, as long as the author is credited and the new creations are licensed under the identical terms.

For reprints contact: reprints@medknow.com

How to cite this article: Maugeri R, Giugno A, Giammalva RG, Guli C, Basile L, Graziano F, et al.A thoracic vertebral localization of a metastasized cutaneous Merkel cell carcinoma: Case report and review of literature. Surg Neurol Int 2017;8:190. http://surgicalneurologyint.com/A-thoracic-vertebral-localization-of-a-metastasizedcutaneous-Merkel-cell-carcinoma:-Case-report-and-review-of-literature/ 
few decades. ${ }^{[1]}$ The mean age at diagnosis of MCCs is 75 years. ${ }^{[16]}$ It typically occurs as a painful reddish lesion, more commonly in sun exposed areas, head, neck, and arms. ${ }^{[10]}$ It is often mistaken for a basal or a squamous skin cancer. ${ }^{[19]}$ Risk factors, besides sun exposure, are: Immunosuppression (MCC is also described transplant patients) and male sex. ${ }^{[19,20]}$ An effective role of human leukocyte antigen (HLA) system in the pathogenesis has not been still clarified as in other malignancies. ${ }^{[1]}$

These tumors tend to local invasiveness, recurrence, and sometimes to distant metastasization. For patients who have distant metastases, the prognosis is even lower. ${ }^{[19]}$ The osseous involvement of the spine is rare: To our knowledge, there are only nine cases reported. ${ }^{[16]}$ In consideration of the very low number of reports, there is no standardized guidelines for this lesions management. We report the tenth case in literature, a 59-year-old patient with a head MCC metastasized to the thoracic spinal column.

\section{CASE DESCRIPTION}

A 59- year-old female was admitted at our Unit of Neurosurgery with a 4-month history of progressive and severe dorsal back pain without neurological signs. The patient had been previously surgically treated in 2007, 2011, and 2013 for a recidivated MCC in the occipital region, firstly mistaken for a basal cell carcinoma. The resection had been followed by several cycles of chemotherapy (5-fluorouracil and cisplatin) and local radiotherapy. In the last surgical excision, a lateral cervical lymph node dissection had been performed. The patient had no other comorbidities or any other cancer and she was not immunocompromised. Two years later, the patient complained the onset of progressive pain in the dorsal region. After the admission at our Unit, a Magnetic Resonance Imaging (MRI) with gadolinium contrast medium of the dorsal spine was performed. A neoplastic involvement of two vertebral bodies (T7 and T8) was visible on the contrast-enhanced Tl-weighted images [Figure la], a local cord impingement and a segmental local kyphosis were visible on T2-weighted images [Figure lb], while and an osteolytic shape was visible on Short-Tl Inversion Recovery (STIR) sequence [Figure lc]. A total body computed tomography (CT) showed several lungs and liver metastases. Neurologic examination was unremarkable. A multidisciplinary consultation was performed, a palliative surgery was decided and the patient was operated employing a posterior dorsal approach based on the use of radiofrequency (RF) thermoablation (MetaSTAR, Dfine, San Jose, USA), followed by the injection of polymethyl methacrylate (PMMA) in T7 and T8 vertebral body and a transpedicle fixation T5-T9.[13] The histopathological analysis of the vertebral body biopsy confirmed that the metastasis is derived from the MCC. Postoperative MRI

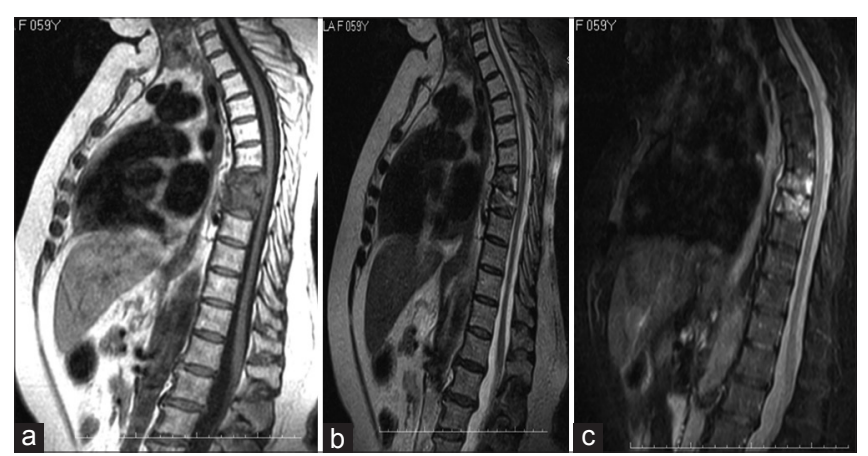

Figure I: (a) Magnetic resonance imaging (MRI): TI-weighted images after gadolinium administration, showing a neoplastic involvement of T7-T8 vertebral body. (b) T2-weighted images showing impingement of the spinal cord and an initial segmental thoracic kyphosis.(c) Short-TI Inversion Recovery sequence shows an osteolytic lesion on T7 and T8 vertebral body

showed a reduction of the neoplastic volume in both involved vertebral bodies (T7 and T8) [Figure 2a and b], while a thoracic CT scan revealed the improvement of the segmental thoracic curvature with correct pedicle fixation and a partial vertebral augmentation [Figure $2 \mathrm{c}$ and $\mathrm{d}$ ]. The postoperative course was uneventful and there was a significant reduction of dorsal pain. The patient is still alive after 8 months, in good general conditions and is going through chemo and radiotherapy.

\section{DISCUSSION}

The spine is the most common site for bone metastases; otherwise it accounts for a very low rate of central nervous system dissemination of local primary tumors. ${ }^{[4]}$

Nowadays, the incidence of spinal secondary involvement is increasing, especially among elderly people, because of longer life expectancy and medical treatments improvement. Seventy percent of cancer patients do have spinal metastases; furthermore, up to $10 \%$ of cancer patients develop metastatic cord compression. The tumors that most frequently spread to the spine are: Breast, lung, renal, prostate, thyroid, melanoma, myeloma, lymphoma, and colorectal cancer. ${ }^{[3,8,23]}$

MCC is a rare malignant neuroendocrine primary skin cancer that arises from epithelial cells known as "touch cells" or "Merkel cells." These cells are involved in mechanic perception, together with sensory neurons located in the dermal-epidermal junction. ${ }^{[25]}$ This tumor shows a remarkable tendency to local invasiveness, while distant metastasization is not frequent. In any case, spinal cord metastasis from MCC is very rarely described. To the best of our knowledge, we are reporting the tenth case in the literature [Table 1]. . $^{2,5,12,15,16,17,18,21,22]}$

Among these nine cases reported, only six had been treated surgically. Despite the introduction of minimally invasive spine endoscopic surgery, no one of the cases reported underwent endoscopic transthoracic removal. ${ }^{[24]}$ 

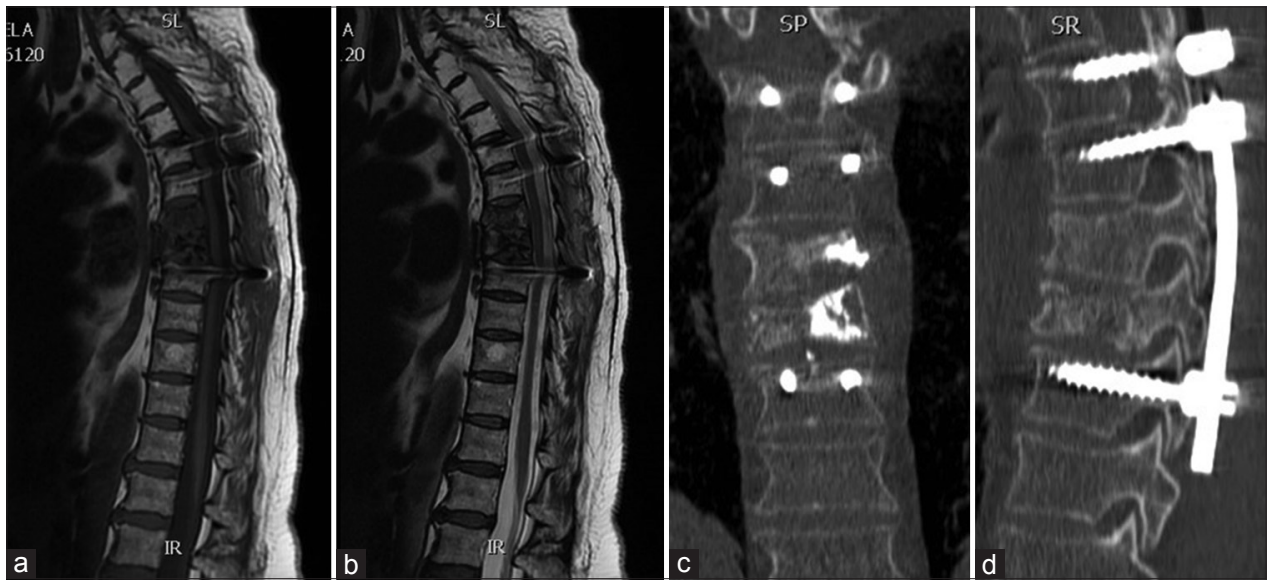

Figure 2: (a) Magnetic resonance imaging (MRI),TI-weighted images after gadolinium administration, showing the reduction of volume of T7-T8 vertebral bodies, with reduced impingement on the spinal cord. (b) T2-weighted images showing an improvement in segmental thoracic kyphosis. (c and d) Computed tomography (CT) scan of the thoracic spine showing the posterior transpedicle fixation and vertebral partial augmentation

Table 1: Cases of Merkel cell carcinomas metastasizing to the vertebral column: Literature review

\begin{tabular}{|c|c|c|c|c|}
\hline Author & Patient & $\begin{array}{l}\text { Metastatic spinal } \\
\text { localization }\end{array}$ & Treatment & Survival \\
\hline Chao TC, 1990 & Female, 23 year & $\begin{array}{l}\text { Thoracic spine } \\
\text { (level not stated) }\end{array}$ & No surgery. & 23 months \\
\hline Moayed S, 2000 & Male, 70 year & Right sacrum. & No surgery. Radiotherapy & $>9$ months (overall survival time not stated) \\
\hline Turgut M, 2002 & Male, 63 year & L5-S1 & $\begin{array}{l}\text { Surgery: Posterior decompression. } \\
\text { Chemotherapy }\end{array}$ & Not stated \\
\hline Payne MM, 2004 & Female, 77 year & T4 & No surgery. Radiotherapy & $>1$ year (overall survival time not stated) \\
\hline Vijay K, 2008 & Female, 57 year & T8, L4, S1. & $\begin{array}{l}\text { Surgery: Posterior decompression } \\
\text { Chemotherapy }\end{array}$ & 1 month \\
\hline Park J, 2009 & Male, 30 year & C6. & Surgery: Posterior decompression. & 37 days \\
\hline Ng G, 2010 & Male, 73 year & T6 & $\begin{array}{l}\text { Surgery: Posterior decompression and } \\
\text { fixation. Chemotherapy }\end{array}$ & $\begin{array}{l}5 \text { weeks (from spinal surgery) - } 7 \text { months } \\
\text { and } 1 \text { week from diagnosis }\end{array}$ \\
\hline Zhao M, 2012 & Male, 54 year & T6, T12-L2 & No surgery & 21 months \\
\hline Madden NA, 2013 & Male, 55 year & T6-T8. & $\begin{array}{l}\text { Surgery: Posterior decompression. } \\
\text { Radiotherapy }\end{array}$ & $>4$ months (overall survival time not stated) \\
\hline Goodwin CR, 2015 & Male, 76 year & T5. & $\begin{array}{l}\text { Surgery: Decompression, corpectomy, } \\
\text { cage placement, and posterior fixation. }\end{array}$ & $>6$ weeks (overall survival time not stated) \\
\hline
\end{tabular}

Our case is the first one in which a segmental dorsal kyphosis was treated with posterior fixation and a $\mathrm{RF}$ coblation of vertebral metastatic lesions. Four out of six patients died short after the treatment, because of the multisystemic failure caused by the illness systemic dissemination. Among those six patients whose treatment was surgery, only four were operated by decompression, ${ }^{[12,17,21,22]}$ while two of them underwent decompression and had an implant of stabilization with screws and rods. ${ }^{[5,16]}$ Among the patients surgically treated with posterior decompression only, the first one presented a L5 metastasis from a primary epigastric MCC, ${ }^{[21]}$ the second one presented a metastatic localization at the eighth dorsal vertebra, ${ }^{[22]}$ while the other two patients had metastases localized respectively at C6 and T6-T8. ${ }^{[12,17]}$ Decompression together with stabilization were performed only in one patient, who showed a large paraspinal localization from $\mathrm{T} 5$ to $\mathrm{T} 7$, with a massive T6 vertebral body involvement. ${ }^{[16]}$ The second patient presented a metastatic localization at $\mathrm{T} 5$, the treatment was: Corpectomy, cage placement, and posterior fixation. ${ }^{[5]}$

All the patients who underwent surgery have died within few months after the operation. In our case, the cutaneous carcinoma in the occipital region was firstly removed in 2007, then in 2011 and 2013. In this last occasion, the removal was followed by lateral cervical lymph node dissection. The patient had no other comorbidities, no other tumor, and she was not immunocompromised. After 2 years, she complained the onset of progressive pain in the dorsal region. An MRI showed a neoplastic involvement of the T7 andT8 vertebral bodies. 
When evaluating a patient with MCC, there are many risk factors to be considered. These factors can increase the likelihood of recurrence or metastases. ${ }^{[19,20]}$ The acronym Asymptomatic, Expanding rapidly, Immune suppression, Older than 50-year old, Ultraviolet (AEIOU) well sums up this tumor's main features: Asymptomatic, expanding rapidly, immune suppression, older than 50-years-old, and ultraviolet (UV) exposure on fair skin. ${ }^{[9]}$ In our case, the patient had no previous history of excessive sun exposure, nor was she immunosuppressed.

The mortality rate for patients diagnosed with a primary skin MCC metastases is very high. MCC management, although not standardized, consists of a wide resection with $1-2 \mathrm{~cm}$ margin, followed by adjuvant therapy. It has been proved that postsurgical radiotherapy does ameliorate the prognosis and reduce local cancer recurrence at 3 years. On the contrary, chemotherapy seems not to interfere with the overall survival. ${ }^{[7]}$ The majority of patients diagnosed with skin cancer metastases often receive palliative treatments. Due to poor prognosis at this stage of disease, surgical treatment is considered only in case of mechanical instability, intractable pain, or progressive neurological dysfunction. ${ }^{[6,12,16,17,21,22,26]}$ Indeed, our patient presented segmental thoracic kyphosis and increasing back pain. After a multidisciplinary consultation, we decided to treat her with a posterior dorsal approach by performing RF thermoablation followed by the injection of PMMA of T7 and $\mathrm{T} 8$ and a transpedicle fixation T5-T9.

Percutaneous imaging-guided ablative therapies using thermal energy sources such as RF, microwave, laser, and high-intensity focused sonography have received much recent attention as minimally invasive strategies for the treatment of focal malignant diseases. The main aim of thermal tumor ablation therapy is to destroy a variable quote of tumor by using heat to kill the malignant cells in a minimally invasive fashion without damaging adjacent vital structures. Possible advantages include low cost, suitability for real-time imaging guidance, and the ability to perform ablative procedures on outpatients. Radiofrequency thermal ablation (RFTA) is considered the treatment of choice for osteoid osteomas, in which it has long been safely used. Other benign conditions (chondroblastoma, osteoblastoma, giant cell tumor, etc.) can also be treated by this technique, which is less invasive than traditional surgical procedures. RFTA ablation is also an option for the palliation of localized, painful osteolytic metastatic, and myeloma lesions. The reduction in pain improves the quality of life of patients with cancer, who often have multiple morbidities and a limited life expectancy. In some cases, these patients are treated with RFTA because conventional therapies (surgery, radiotherapy, chemotherapy, etc.) have been exhausted. In other cases, it is combined with conventional therapies or other percutaneous treatments, e.g., cementoplasty, offering faster pain relief and bone strengthening. ${ }^{[13]}$

In this case, the postoperative course was uneventful and followed by a further adjuvant therapy. The patient is still alive and in good general conditions after 8 months. This case report suggests that in the advanced stage of MCC, spinal cord metastases surgical treatment must be considered if the patient complains back pain, even in absence of neural signs or symptoms.

\section{CONCLUSION}

MCC is an uncommon nonmelanoma skin cancer. There is a high-risk subgroup that develops distant metastases to lungs, mediastinum, liver, or bone, which are associated to a bad prognosis. Spinal localization is very rarely reported in literature. However, this hypothesis must be considered in presence of a patient having a history of MCC and complaining back pain, even in absence of neural signs or symptoms. Our case demonstrates that a selected surgery of vertebral metastases may permit improved survival and better life quality. Larger multicenter studies are needed, in order to determine the real risk of metastases and death connected to this cancer, as well as to confirm the role of surgical and adjuvant therapies in this specific subgroup of patients with MCC, to further guide management.

\section{Financial support and sponsorship}

Nil.

\section{Conflicts of interest}

There are no conflicts of interest.

\section{REFERENCES}

I. Agelli M, Clegg LX. Epidemiology of primary Merkel cell carcinoma in the United States. J Am Acad Dermatol 2003;49:832-4I.

2. Chao TC, Park JM, Rhee H, Greager JA. Merkel cell tumor of the back detected during pregnancy. Plast Reconstr Surg 1990;86:347-5I.

3. Choi D, Crockard A, Bunger C, Harms J, Kawahara N, Mazel C, et al. Review of metastatic spine tumour classification and indications for surgery: The consensus statement of the Global Spine Tumour Study Group. Eur Spine J 2010;19:215-22.

4. Della Pepa GM, Visocchi M. Intracranial metastasis from a "giant" nonoperated sacrococcygeal chordoma: An underestimated metastatic potential? Br J Neurosurg 2014;28:564-5.

5. Goodwin CR, Mehta AI, Adogwa O, Sarabia-Estrada R, Sciubba DM. Merkel Cell Spinal Metastasis: Management in the Setting of a Poor Prognosis. Global Spine J 20I5;5:e39-43.

6. Goodwin CR, Sankey EW, Liu A, Elder BD, Kosztowski T, Lo SL, et al. A systematic review of clinical outcomes for patients diagnosed with skin cancer spinal metastases. J Neurosurg Spine 2016;24:837-49.

7. Hasan S, Liu L, Triplet J, Li Z, Mansur D. The role of postoperative radiation and chemioradiation in Merkel cell carcinoma: A systematic review of the literature. Front Oncol 2013;3:276.

8. Grasso G, Meli F, Patti R, Giambartino F, Florena AM, lacopino DG. Intramedullary spinal cord tumor presenting as the initial manifestation of 
metastatic colon cancer: Case report and review of the literature. Spinal Cord 2007;45:793-6.

9. Heath M, Jaimes N, Lemos B, et al. Clinical characteristics of Merkel cell carcinoma at diagnosis in 195 patients: The AEIOU features. J Am Acad Dermatol 2008;58:375-8I.

10. Hitchcock CL, Bland KI, Laney RG $3^{\text {rd }}$, Franzini D, Harris B, Copeland EM $3^{\text {rd }}$. Neuroendocrine (Merkel cell) cancer of the skin. Its natural history, diagnosis, and treatment. Ann Surg 1988;207:201-7.

II. La Torre D, Maugeri R, Angileri FF, Pezzino G, Conti A, Cardali SM, et al. Human leukocyte antigen frequency in human high-grade gliomas: A case-control study in Sicily. Neurosurgery 2009;64:1082-8.

12. Madden NA, Thomas PA, Johnson PL, Anderson KK, Arnold PM. Thoracic spinal metastasis of merkel cell carcinoma in an immunocompromised patient: Case report. Evid Based Spine Care J 2013;4:54-8.

13. Maugeri R, Graziano F, Basile L, Guli C, Giugno A, Giammalva GR, et al. Reconstruction of Vertebral Body After Radiofrequency Ablation and Augmentation in Dorsolumbar Metastatic Vertebral Fracture: Analysis of Clinical and Radiological Outcome in a Clinical Series of 18 Patients. Acta Neurochir Suppl 2017; 124:8I-6.

14. Merkel F. Tastzellen and Tastkoperchen bei den Hausthieren und beim Menschen. Arch Mikrosk Anat 1875; I I:636.

15. Moayed S, Maldjianb C, Adam R, Bonakdarpour A. Magnetic resonance imaging appearance of metastatic Merkel cell carcinoma to the sacrum and epidural space. Magn Reson Imaging 2000; 18:1039-42.

16. NG G, Lenehan B, Street J. Metastatic Merkel cell carcinoma of the spine.
Case Reports. J Clin Neurosci 2010; 17:1069-7I.

I7. Park J, Park Y. Cervical spinal metastasis of Merkel cell carcinoma. Korean J Spine 2009;6:197-200.

18. Payne MM, Rader AE, McCarthy DM, Rodgers WH. Merkel cell carcinoma in a malignant pleural effusion: Case report. Cytojournal 2004;1:5.

19. Saini AT, Miles BA. Merkel cell carcinoma of the head and neck: Pathogenesis, current and emerging treatment options. OncoTargets Ther 20I5;8:2I57-67.

20. Sulowicz J, Wojas-Pelc A, Sulowicz W. Merkel cell carcinoma in patient after organ transplantation. Przegl Lek 2015;72:83-6.

21. Turgut M, Gokpinar D, Barutca S, Erkuș M. Lumbosacral metastatic extradural Merkel cell carcinoma causing nerve root compression - case report. Neurol Med Chir (Tokyo) 2002;42:78-80.

22. Vijay K, Venkateswaran K, Shetty AP, Rajasekaran S. Spinal extra-dural metastasis from Merkel cell carcinoma: A rare cause of paraplegia. Eur Spine J 2008; 17:S267-70.

23. Visocchi M, La Rocca G, D'Ercole M, Conforti G, Roselli R, Lauriola L, et al. Isolated intramedullary cervical spinal cord metastasis from colon cancer: A surgical or medical challenge? J Neurosurg Sci 2016;60:405-7.

24. Visocchi M, Masferrer R, Sonntag VHK, Dickman: Thoracoscopic approaches to the thoracic spine. Acta Neurochir (Wien Austria) 1998;140:737-44.

25. Woo SH, Lumpkin EA, Patapoutian A. Merkel cells and neurons keep in touch. Trends Cell Biol 20I5;25;74-8I.

26. Zhao M, Meng MB. Merkel cell carcinoma with lymph node metastasis in the absence of a primary site: Case report and literature review. Oncol Lett 2012;4:1329-34. 